\title{
ABET CRITERIA 2000 AND BIOMEDICAL ENGINEERING; SOME INITIAL EVALUATOR IMPRESSIONS
}

\author{
John D. Enderle, University of Connecticut
}

\begin{abstract}
The Accreditation Board for Engineering and Technology (ABET) has after almost a decade of effort developed a new program review process called "Engineering Criteria 2000," a change from a prescriptive evaluation to one based on program defined missions and objectives with an emphasis on outcomes. The purpose of this paper is to provide the author's general impressions of Engineering Criteria 2000 (EC2000). The author is a trained ABET biomedical engineering program evaluator who has conducted one visit under EC2000, and two evaluations under the pre- EC2000. Note clearly that information received from the ABET site visit conducted under EC2000 by the author is not revealed in this report, but rather this is a report providing a general reaction to the new review process.
\end{abstract}

\section{Introduction}

ABET is an organization responsible for monitoring, evaluating, and certifying the quality of engineering, engineering technology, and engineering related education in the United States. It's vision is: "ABET will provide world leadership to assure quality and stimulate innovation in engineering, technology and applied science education." The new evaluation procedure, EC2000, includes many of the past requirements, and also includes the practice of continuous improvement with input from constituencies, process focus, and outcome and assessment linked to objectives. The overall emphasis, as before, is to set the minimum knowledge level for entry into the engineering profession. The evaluation is based on student, faculty, facilities, institutional support and financial resources linked to the program. An accompanying paper ${ }^{1}$ in this session describes the preparation in response to an EC2000 site visit, the EC2000 Self-Study Report. This paper focuses on a general reaction to the new review process from the standpoint of the evaluator/visitor of the biomedical engineering program. Information about ABET EC2000 and definitions are found at http://www.abet.org.

\section{Visit Process}

Work on the site visit for the evaluator actually occurs well before the site visit with a review of the EC2000 Self-Study Report provided by the program. A detailed description of the SelfStudy Report is provided in [1] with a biomedical engineering emphasis and at the ABET WWW site. The evaluator typically spends a few days thoroughly reviewing the information in the SelfStudy Report and completes the Program Report form on the Curriculum Analysis, Transcript Analysis, Program Audit Form, and Faculty Analysis well before making the site visit. 
The visit typically begins on Sunday (Day 0) with the assembling of the ABET evaluator team. The team then travels on-campus to make an initial inspection of the course materials and documentation related to the program. The team re-assembles for dinner and reviews the previsit assessments of the programs.

On Monday (Day 1) the team meets with the Dean and the Dean's invited guests. This often includes Department/Program Heads and Associate Deans. The Dean presents an update of the institution's implementation of Engineering Criteria 2000, processes that are common to all units and key outcomes and continuous improvement efforts. The program evaluator then meets with the Program Head to discuss educational objectives, involvement of constituencies, programlevel processes, outcomes, and continuous improvement efforts. The evaluator meets with faculty and students to determine key strengths and weaknesses of the program throughout the day. During the luncheon, various officials and guests of the institution are present to discuss the program and the institution. During the afternoon, the evaluators visit various support units on campus (e.g., biology department, library, computing center). The team gathers for dinner that evening to discuss an updated assessment of the programs, assessments from support areas and any issues arising from the visit. Afterward, the evaluator prepares a draft exit interview program statement. This statement addresses each of the first seven Engineering Criteria 2000, documenting deficiencies, weaknesses, concerns, and strengths. Suggestions for improvement are usually provided in this report. Also described are the evaluator's findings concerning evaluation and assessment processes in place for the unit, and the use of processes to improve the effectiveness of the program.

On Tuesday (Day 2) the team provides copies of the first draft of the Exit Interview Program Statement to the Team Chair at the beginning of the day. The evaluator inspects classrooms, laboratories and offices to assess the adequacy of allocated space, furnishings, and equipment available to students, faculty and support staff. The evaluator completes meetings with remaining institutional representatives. The evaluator then revises the draft exit interview program statement, and then debriefs the Program Head. In this meeting the evaluator clarifies issues, describes program strengths and weaknesses. The team reassembles for a private lunch and informally shares program findings. Each of the exit interview program statements is finalized. The evaluator provides the Team Chair with a copy of the exit interview program statement and program report at the conclusion of the luncheon. The team then gathers and conducts an exit interview with the Institution President and his/her guests.

\section{Biomedical Engineering Program}

The biomedical engineering (bioengineering) program criteria have been substantially simplified to the following.

\section{"1. Curriculum}

The structure of the curriculum must provide both breadth and depth across the range of engineering topics implied by the title of the program.

The program must demonstrate that graduate have: an understanding of biology and physiology, and the capability to apply advanced mathematics (including differential equations and statistics), science, and engineering to solve the problems at the interface of engineering and biology; the ability to make measurements on and interpret data from living systems, addressing the problems associated with the interaction between living and non-living materials and systems." 
No longer are the previously more prescriptive criteria on faculty size, curriculum requirements on engineering science, mathematics, basic sciences (minimum of $1 / 4$ year of biology and $1 / 4$ year of chemistry), engineering design, and biomedical engineering laboratory experience. In reality, these elements are still there, but made more flexible according to the program mission and objectives.

\section{Assessment}

EC2000 includes the practice of regular assessment studies and continuous improvement with input from the constituencies, process focus and outcome and assessment linked to objectives. This is one of the major changes involved in the new criteria, and one that causes the most anxiety among programs being evaluated. It should be noted that successful implementation of assessment and continuous improvement are not done right before an ABET visit, but must be a regular and ongoing part of the operation of the program. It is hoped that this process will encourage new and innovative approaches to engineering education and its assessment. Under EC2000, programs define the mission and objectives to meet the needs of the students, industry and other important constituents. This allows for program differentiation from institution to institution. Objectives are tied to outcomes that are supported via assessment measures. The assessment process is one that improves the quality of the program (curriculum) through measurement, and ensures that students achieve program outcomes before the certification of graduation. Assessment is a faculty activity that should result in change such as adoption of new textbooks, teaching techniques and laboratory procedures/experiments. It is not the responsibility of the program evaluator to discover the fruits of assessment; it is the responsibility of the faculty to demonstrate how assessment has caused changes in the program.

Assessment and continuous improvement require a plan of action. To demonstrate that graduates have achieved desired outcomes, some programs use student portfolios, collecting student work from the freshman year to the senior year using a WWW based approach. This tool is useful in demonstrating that outcomes have been achieved. Others use an exit interview for all graduating students that provide important program feedback. This interview is in addition to course evaluations which are important metrics for individual instructor and course improvement. Another mechanism is to use national exams, such as the EIT exam; this exam also allows for comparison among institutions. Alumni surveys that document professional accomplishments and career developments are another useful tool that can be carried out over a period of years (say 2 and 5 years after graduation). Employer surveys and placement of graduates are other important metric of performance.

Continuous improvement of the program is the ongoing responsibility of the faculty. This is evident by faculty meetings with this topic as the major theme, or periodic faculty retreats. Creating a working advisory board from industry and current students is also another mechanism to provide feedback.

Overall, it is the program's responsibility to demonstrate that assessment and continuous improvement has occurred in a clear and direct manner. It is a mistake to provide the evaluator with reams of data that has not been analyzed and used to make changes in the program.

V. Major Design Experience 
Students are expected to engage in a culminating major design experience based on the knowledge and skills required in earlier course work. This project must incorporate engineering standards and realistic constraints, including most of the following considerations: economic, environmental, sustainability, manufacturability, ethical, health and safety, social and political. A multidisciplinary team project during this experience or in previous courses is expected in the program. A multidisciplinary team project for biomedical engineering programs is most easily accomplished via a project in which a student from each subspecialty is included on the team (e.g., biomechanics, biochemical, bioelectrical, biomaterial, biocomputing, etc.). No longer is there a requirement for the number of design credits in each course be counted, just a significant culminating design project that prepares students for entering engineering practice. Another option for biomedical engineering design projects is the National Science Foundation Program on design projects to aid persons with disabilities ${ }^{2}$. This program combines the academic requirement of a design experience with enhanced educational opportunities for students, and improved the quality of life for disabled individuals. Students and university faculty provide, through their normal ABET accredited senior design class, engineering time to design and build a device or software for a person with disabilities, and the NSF provides funds, competitively awarded, for supplies, equipment and fabrication costs for the design projects. Projects are described in an annual publication funded by the $\mathrm{NSF}^{3}$.

\section{Conclusion}

EC2000 has had a tremendous impact on the way faculty view the accreditation process. Certainly, the role of and use of mission, objectives, outcomes, assessment and continuous improvement are new to the accreditation process in Engineering Criteria 2000. This is true of all programs, however, and not just for bioengineering. For bioengineering, there are fewer requirements in EC2000 than the previous criteria. This allows each institution to fully develop the biomedical engineering program based on the needs of their constituents, such as local industries. As a result, a greater diversity and differentiation in programs will exist, offering students a greater selection in biomedical engineering curriculums across the United States.

Bibliography:

1. Gassert, J.D., A View Of From Both Sides Of Abet Criteria 2000; The Reviewed And The Reviewers. Proceedings of the ASEE Annual Conference and Exposition, June 2000, In Press.

2. Enderle, J.D., An Overview on the National Science Foundation Program on Senior Design Projects to Aid Persons With Disabilities. International Journal on Engineering Education, Vol. 15, No. 4, 288-297, 1999.

3. Enderle, J.D. and Hallowell, B. (Editors), National Science Foundation 1996 Engineering Senior Design Projects to Aid Persons with Disabilities. Creative Learning Press, Inc., Mansfield Center, Connecticut, 1999,250 pages. (Available for viewing at: http://nsf-pad.bme.uconn.edu).

Acknowledgement:

Much of this paper is derived, either directly or indirectly, from material provided by ABET.

John D. Enderle, Ph.D.

Received the B.S., M.E., and Ph.D. degrees in biomedical engineering, and M.E. degree in electrical engineering from Rensselaer Polytechnic Institute, Troy, New York, in 1975, 1977, 1980, and 1978, respectively. He is a professor of electrical engineering and program director of biomedical engineering at the University of Connecticut. 
Dr. Enderle is a Fellow of the IEEE and AIMBE, and a Teaching Fellow at UConn. He is also an ABET EAC program evaluator for Biomedical Engineering. 